\title{
Ghettos of the mind: the empirical behaviour of indices of segregation and diversity
}

Link to publication record in Manchester Research Explorer

\section{Citation for published version (APA):}

Simpson, L. (2006). Ghettos of the mind: the empirical behaviour of indices of segregation and diversity. (CCSR Working Paper).

\section{Citing this paper}

Please note that where the full-text provided on Manchester Research Explorer is the Author Accepted Manuscript or Proof version this may differ from the final Published version. If citing, it is advised that you check and use the publisher's definitive version.

\section{General rights}

Copyright and moral rights for the publications made accessible in the Research Explorer are retained by the authors and/or other copyright owners and it is a condition of accessing publications that users recognise and abide by the legal requirements associated with these rights.

\section{Takedown policy}

If you believe that this document breaches copyright please refer to the University of Manchester's Takedown Procedures [http://man.ac.uk/04Y6Bo] or contact uml.scholarlycommunications@manchester.ac.uk providing relevant details, so we can investigate your claim.

\section{OPEN ACCESS}




\section{MANCHESTER}

\section{Cathie Marsh Centre for Census and Survey Research}

\section{Ghettos of the mind: the empirical}

behaviour of indices of segregation and diversity

CCSR Working Paper 2006-06

Ludi Simpson

ludi.simpson@manchester.ac.uk 


\title{
Ghettos of the mind: the empirical behaviour of indices of segregation and diversity
}

\author{
Ludi Simpson \\ University of Manchester, UK
}

Address for correspondence Ludi Simpson, Cathie Marsh Centre for Census and Survey Research, Oxford Road, Manchester M13 9PL, UK.

\begin{abstract}
Summary. The impact of immigration on social cohesion is a political issue, expressed as a fear that racially skewed residential patterns represent ghettos which prevent integration. Residential patterns have been measured by indices of segregation. The range of indices is reviewed in this paper and measured empirically for England and Wales using census data for 1991 and 2001. There has been an increase in residential mixing as a result of growing minority populations and their more even spread across localities. These two trends are identified by two commonly used indices of segregation which are moving in opposite directions for Muslim groups. The sensitivity of each index to modifiable area boundaries makes them unsuitable for evaluation of relative cities' relative performance. The residential patterns of cities after immigration are more clearly understood using demographic measures of migration, births and deaths.
\end{abstract}

Keywords: integration; segregation; index; ethnic group; migration; race

\section{Introduction}

International migration is a feature of a world with national boundaries. This paper reviews the indices commonly used to measure the residential patterns resulting from international migration.

Most residents of North America, Europe and probably of much of the world, are aware of ancestry originating outside our country of current residence. We respond with a sense of pride in the exotic, complex nature of our identity. But in North America and Europe current international migration is also viewed with suspicion and concern. Concentrations of residents with non-indigenous cultural and family roots have come to be viewed negatively in many policy arena. In Britain, reports on urban tensions in 2001 noted "the very worrying drift towards self-segregation, the necessity of arresting and reversing this process" (Ouseley, 2001: foreword) and "the depth of polarisation of our towns and cities" (Cantle, 2001: 9). The reports led to government insistence that each local authority defuse social tensions by implementing a local 'community cohesion plan'. In 2005, the government's Commission for Racial Equality felt that in spite of these social policies "Residentially, some districts are on their way to becoming fully fledged ghettoes - black holes into which no-one goes without fear and trepidation, and from which no-one ever escapes undamaged" (Phillips, 2005). The Commission's head of policy considers segregation as one of the two key problems facing race relations (the other being pervasive inequality): 
We are also living in a society that is becoming more segregated by ethnic group. This is both residential and social. The census shows us that 80 local authority areas saw both a decrease in the White population and increase in the ethnic minority population between 1991 and 2001.” (Johnson, 2006).

Policy concerns regarding race have for centuries inspired applied statistical research (for a review see Zuberi, 2001). Indices of residential segregation were developed from the Chicago School's work on inter-group relations, including comparison of racial residential patterns (for example Wirth, 1928; Duncan and Duncan, 1955; Lieberson, 1963). European and North American urban studies have continued to focus on the same indices and new versions of them. It has been usual practice to associate high values of measured segregation with a lack of social integration that is threatening to the social fabric of society (Fortuijn et al., 1998). This association has not been universal and does not represent an assumption of this paper, but explains the continuing fascination of geographers and politicians with measuring residential segregation.

Typical of research reports addressing residential segregation, a recent review of English cities for the UK government uses the Index of Dissimilarity (defined below) in one of its fourteen chapters on social, demographic and economic change (Parkinson et al., 2006). The index is used to measure both integration and segregation, considered to be at opposite ends of the scale which "varies in value between 0 and 100, with values under 40 generally considered as low segregation, 40 -59 moderately high, 60-69 high, and 70+ very high” (Vol 1: 146). The report tabulates values of the index to directly compare cities, finding for example that "segregation is significantly higher in cities in the north and west of England". It identifies change over time for each city by comparing the segregation between electoral wards as they were defined for the 1991 and 2001 census outputs, finding that segregation “declined between 1991 and 2001 in 48 out of 56 cities” (Vol 1, 153). In only two cases was the increase significant. These two received adverse publicity for their trend opposite to the general increase in social integration; we shall see that in both cases the publicity was unwarranted because the indices were used misleadingly.

The Index of Dissimilarity is one among several indices that are recognised and commonly used in research literature on segregation. After summarising the demography of ethnic groups in Britain, this paper defines these indices and reviews their use to measure different aspects of residential segregation and diversity. The paper then measures the indices' values across electoral wards within England and Wales for 1991 and 2001, to assess whether a different dimension of change is measured by each index, and to act as a benchmark for further empirical evaluations of the indices.

Some interpretations of the indices have been criticised for lack of relevance to the social conditions which should define ghettos, for an offensive focus on numbers of Black and Asian people instead of recognition of cosmopolitan realities (GLA, 2005), for insensitivity to migration which more directly reflects 'self-segregation' (Simpson, 2004), and for lack of relevance to people's housing choices and aspirations (Phillips, 2006). The association between segregation and negative outcomes has been questioned, citing the social solidarity gained in diverse areas, which historically has preceded and enabled integration (Peleman, 2002; Rex, 1981). This paper also interprets the indices but its empirical focus is their proper use to compare areas, to 
identify low and high levels of segregation, and to monitor segregation over time. To answer these questions, the paper examines the sensitivity of indices to geographical definition of the areas compared.

The results are then interpreted in the wider context of historical demographic and social change, which suggests that current trends in the ethnic group dimension of residential geography are similar in nature to those following Irish and Jewish immigration. Identification of research priorities focuses on the dynamic processes of population and social change rather than the current racial geography which indices crudely describe.

\section{Demographic change}

Figure 1 shows the net contribution of migration and of natural effects (births less deaths) to population change, for each ethnic group in England that is comparable across the period between 1991 and $2001^{1}$. The African group nearly doubled in size, the majority of its growth being due to immigration. The Caribbean group, in contrast, lost from migration during the decade. Each minority group grew significantly from natural change because the largest cohorts of immigrants are not yet elderly. The growth from natural change is a greater source of growth than is immigration for the Indian, Pakistani and Bangladeshi populations.

[Figure 1 about here]

This growth is confirmed by the State of the English Cities report (Parkinson et al., 2006) which also shows that growth of the non-White populations taken as a whole has occurred in every region and every type of city. This growth 'in situ', mainly due to a young population with fewer deaths than births, will help to explain the values of segregation and diversity indices when applied to England and Wales. The growth is characteristic of population with origins in the post-second-world-war immigration to Europe. It is in contrast to the Black and White populations of the USA for which the indices were first developed. 


\section{Indices of segregation and diversity}

'Segregation' has been used in public debates to express several different ideas. Four distinct concepts are identified below together with indices by which they have been measured: geographical evenness of groups, exposure to other groups, movement towards one's own group, and local diversity. Other classifications are possible. Massey and Denton's comprehensive and influential review (1988) suggests that "Viewing segregation as a multidimensional construct will, we hope, encourage research into the many ways that segregation can affect people's lives. Its effects are easier to imagine in terms of concrete spatial outcomes such as evenness, exposure, concentration, centralization, and clustering, than in terms of the ambiguous idea of 'segregation'." (32) They find empirically through factor analysis that indices measuring these five outcomes do represent different dimensions when measured for US cities. Exposure and evenness account for more than two thirds of variation between areas in their study, and correspond to the first two concepts considered below, while concentration, centralization and clustering refer to the occupation of physical space, central city areas, and contiguous areas respectively, and have not so often been used. Instead, the measurement of movement and diversity is included below, to represent important dimensions of current political debate.

\subsection{Evenness: an unequal geographical spread}

Here segregation is conceived as the spread of a group $g$ relative to the rest of the population (denoted $\bar{g}$ ). It is usually measured by comparing the share of each locality $i$ in the group's total population, with the locality's share of the rest of the population, in the index of dissimilarity (ID). The locality absolute differences in shares are summed and divided by 2 so that the index takes values between 0 and 1 . $N_{g i}$ refers to the population of group g in locality $i$, while summation over an index is represented by the $\bullet$ symbol:

$$
I D=0.5 \sum_{i} \operatorname{abs}\left(\left(N_{g i} / N_{g .}\right)-\left(N_{\overline{g i}} / N_{\bar{g} .}\right)\right)
$$

$I D$ is used so commonly that it is often known simply as the segregation index. Any value of $I D$ has a simple interpretation: it is the proportion of the group's population which would have to move areas, to become distributed across areas in the same way as the rest of the population. It may also be used to compare the spread of any two groups, by replacing the locality's share of $\bar{g}$ (the second term in the formula) with the area's share of a second group $h$. Other indices of evenness include Theil's entropy index and the Gini coefficient, but these are not common in the literature of residential segregation.

Voas and Williamson (2000) discuss the properties of ID when the population of a group is small relative to the number of areas in the region under study. Gorard and Taylor (2002) point out how the index can be modified when individuals change from one group to another, as with children's entitlement to welfare benefits. They relate a group's spread through areas to the spread of the whole of the population rather than the remainder of the population. This modification is not necessarily suitable for the general use of $I D$ as they claim because it is correlated to the group's overall proportion in the population which itself changes over time. The same modification is used by Dorling and Rees (2003).

\subsection{Exposure: a high proportion of particular ethnic groups in a locality}


This is the simplest concept, often used in the phrase 'a segregated area'. It often refers to a high proportion of all groups other than White taken together, but might equally refer to a specific group - the proportion of Muslims, the proportion of Chinese. It is the growing proportion of ethnic minorities and decreasing proportion of White residents within Britain's cities that has concerned the Commission for Racial Equality, referred to in the introduction. Some authors refer to enclaves of ethnic minorities; Johnston, Forrest and Poulsen (2002) define mixed and polarised enclaves, the latter being a locality where White residents are less than $30 \%$ of the total, and one group accounts for at least two thirds of the non-White residents. Many similar publications by the same authors also use 'threshold analysis', displaying the cumulative distribution function of the group's proportion in the local population, a graphical expansion of the isolation index (Poulsen et al., 2004). All these measures identify localities with relatively large populations of non-White groups and therefore the exposure or lack of exposure of one group to another. These proportions can change independently of the evenness of a group's residents through localities. Most simply they may increase in all localities with no impact on evenness.

Measured across a city or a whole country, the proportion of a group in the population varies across localities $i$. The Index of Isolation, conventionally written $P^{*}$, measures the group $g$ population as a proportion within the local population, averaged across all the members of that group (Lieberson, 1963):

$$
P_{g}^{*}=\sum_{i}\left(N_{g i} / N_{g .}\right)\left(N_{g i} / N_{\cdot i}\right)
$$

For each area $i$, the left-hand term is the proportion of the group's population that lives there; it is multiplied by the group population as a proportion within the local population. Like the Index of Dissimilarity, $P^{*}$ has a simple interpretation. It can be usefully thought of as the probability that a member of the group will meet someone of their own group locally. It is equivalently the probability that a member of that group will not meet someone of another group, from which the label 'index of isolation' derives. The upper value of 100 for the isolation index means such high segregation that all members of the group are in areas where no other groups live.

There are many variations of the index of isolation. It can be adapted to represent the isolation of one group from another by replacing the right hand local area proportion with that for a second group. $P^{*}$ is dependent on the overall population composition since relatively large groups are more likely to live with many of their own group. $P^{*}$ has a lower limit of this proportion $P_{g}=N_{\mathrm{g}} / N_{. .}$, and an upper limit of 1 . Johnston, Wilson and Burgess (2004) reduce the dependence of $P^{*}$ on population size by computing a 'modified index of isolation' equal to $P_{g}{ }^{*}-P_{g}$ which takes values between 0 and $1-P_{g}$. Full independence from relative population size would require further division by $\left(1-P_{g}\right)$ :

$$
\left(\sum_{i}\left(N_{g i} / N_{g .}\right)\left(N_{g i} / N_{. i}\right)-N_{g .} / N_{. .}\right) /\left(1-N_{g \cdot} / N_{. .}\right)
$$

Burgess et al. (2005) use this form, which White (1986) shows is equivalent to the intra-class correlation ratio (variation between areas of the proportion of a group divided by the overall variation in membership of that group). Although attractive for its independence from overall population composition, this standardised Index of Isolation is dismissed by Massey and Denton (1988) for confounding the two 
dimensions of evenness and exposure and for losing the straightforward interpretation of the unstandardised index as the average local proportion of the group. These criticisms can also be levelled at the Johnston et al. modified index of isolation, which in addition remains correlated to population composition.

Unlike $P^{*}$, the $I D$ is not affected by the overall population composition but only by its distribution through the areas. The two indices can and do change over time in different directions, and as we shall see this is what would be expected after significant streams of immigration.

\subsection{Movement: migration towards one's own group}

Public debate already referred to has made much of the idea of 'self-segregation' and its colour-specific equivalent 'White flight'. The suggestion is that residents of a group are choosing to live with others of the same group. A retreat into one's own localities is not measured by the proportions of people in each locality but by the extent of their movement towards localities that already have relatively high proportions of one's own group. It is most directly measured by the migration of a group to and from areas in which the group has greatest presence, for example by the net migration $M$ (out-migrants subtracted from in-migrants) of a group towards the localities $X$ where it is most prevalent, expressed as a proportion of its population in those areas. This is the Migration Index developed for this paper:

$$
M_{g}^{X}=\sum_{i \in X}\left(M_{g i}^{\text {in }}-M_{g i}^{\text {out }}\right) / \sum_{i \in X} N_{g i}
$$

For debates about segregation, the net impact of migration within the country, after immigration, reflects particular concern. International migration may be of additional interest. The areas $\mathrm{X}$ with greatest presence of non-White population are defined in this paper as those with highest percentage of non-White population that contain in total one fifth of its population. The Migration Index is then measured for each group g. Migration to and from this fifth quintile can be contrasted with migration to and from the first quintile which contains the same total non-White population in low proportion spread across many more areas.

\subsection{Diversity: approximate equality of numbers of each group}

The diversity of groups within an area may be measured simply by whether the proportion of White residents and all other residents both exceed an arbitrary specified value, say $10 \%$ or $25 \%$. The proportion of mixed areas in a region or country gives a simple Index of Mixing (Simpson, 2005).

The Reciprocal Diversity Index developed by ecologists, shows how close a set of species are to equal numbers within an area:

$$
R D I_{i}=1 / \sum_{g}\left(\frac{N_{g i}}{N_{\cdot i}}\right)^{2}
$$

Unlike the other measures discussed here, the Reciprocal Diversity Index captures the diversity between several groups in an area, appropriately to London's cosmopolitan population where the Greater London Authority (2005) computed the mean index value across electoral wards in both 1991 and 2001. The index takes values between 1 and the number of groups $n g$, and can be standardised to the range $[0,1]$ by deduction of 1 and division by (ng-1). In that case, the value of 1 represents an equal number of each group in the area. 
Indices of diversity are strongly influenced by the overall population composition of the region under study. A set of groups that are close in population size for the region as a whole will tend to have higher diversity when measured as an average across its local areas.

\subsection{Interpretation of indices}

The Migration Index is the only measure of the process of population change. Nonetheless, the impact of migration on an area is the net result of housing and economic pressures, social networks and individual motivations which are not directly measured by the index. In the same way, the measures of exposure, evenness and diversity do not measure the multiple reasons for patterns of residence. Later discussion will refer again to the poor explanatory power of indices. The next sections examine the value of selected indices for areas within England and Wales, and their sensitivity to geographical boundaries.

\section{Data sources and index values for England and Wales 1991-2001}

Racial and ethnic categories are not common in administrative or population datasets which are necessary to describe settlement patterns (SEU, 2000; Coleman and Salt, 1996). The population census in Great Britain has included a question on 'ethnic group' in 1991 and 2001, which is here used to evaluate six of the indices of segregation and diversity, including at least one representative for each of the four dimensions discussed above. The ethnic group question changed between the two censuses. Results for the five largest stable groups are used in this paper: White, Caribbean, Indian, Pakistani and Bangladeshi.

Data for the total population of each ethnic group are derived from Table S06 for 1991 and Table CAST03 for 2001, which are published for all standard areas: Council Districts, each comprising several Electoral Wards, which in turn comprise several small Output Areas (named Enumeration Districts in 1991). Each Census was subject to different levels of undercount and to differences in population definition affecting students in particular. However, full population estimates are not available to evaluate the impact of these marginal aspects of data quality and definition on the values of segregation indices. It is sometimes the marginal changes in indices which draw the attention and are the result of changing data quality, as will be discussed later. Data using the ethnic group questions for both 1991 and 2001 are not released outside England and Wales.

Additional data are required for the Migration Index, and are derived from Table KS24 for 2001. The 1991 migration data are available only for districts and not for smaller areas. Migrants during the year before the census are counted. The difference between the numbers of migrants entering and leaving the area has been expressed as a proportion of the area's population at the time of the census. This is a close approximation to the true rate which would be expressed as a proportion of the population in the year before the census which is not known.

As a preliminary summary, Table 1 shows a threshold analysis of the 'exposure' of the White group to other groups. In part (a) of the table, the 376 Districts in England and Wales have been sorted according to the increasing proportion of their population recorded in ethnic groups other than White, and allocated to quintiles, each of which contains approximately one fifth of the non-White population. In parts (b) and (c) the same analysis is repeated for the 8,850 electoral wards in England and Wales with 
mean six thousand residents, and for the 175,434 Output Areas which each contain about 200-400 residents. The totals of each part of the table do not agree exactly due to the random rounding of small census output cells as part of the Office for National Statistics' programme to limit disclosure of potentially confidential information; this rounding particularly affects the statistics for small Output Areas.

[Table 1 about here]

England and Wales' population in ethnic groups other than White is clustered. It numbers $4.5 \mathrm{~m}$ or $9 \%$ of the total, but one fifth of these in the first quintile live spread through 306 local authority districts where they make up 3\% of the population. The same number of non-White residents in the fifth quintile live in six Districts where they are $36 \%$ of the population (Leicester, Bradford, Ealing, Brent, Newham and Birmingham). The same analysis for wards and for output areas in the lower part of Table 1 shows that smaller areas have a greater variation in the White and non-White populations. The clustering is more evident for smaller areas. One fifth of the nonWhite population reside where their immediate locality (Output Area) has on average three quarters non-White population and one quarter White.

Table 2 shows the values of selected indices from each conceptual dimension of segregation, measured across the electoral wards of England and Wales in 1991 and in 2001, and multiplied by 100 for greater legibility. The number and boundaries of wards are regularly reviewed, resulting in a reduction in the number of wards between the two years from 9,509 to 8,850, with average population size correspondingly increasing from 5,247 to 5,880 . In the next section these changes will be seen to have some impact on comparisons over time, but do not detract from the general picture shown by Table 2 .

[Table 2 about here]

First, evenness, represented by ID is 59\% for the contrast between White residents and all others. It has decreased since 1991, indicating a more even distribution between White and all other residents. The ID is greater for each of the individual groups taken separately, because they do not each live in the same places in England and Wales. The groups with most recent history of immigration to England and Wales are most clustered, the Pakistani and Bangladeshi populations. For every group the average clustering has decreased over the decade by 2-3 percentage points.

Second, exposure as represented by the Index of Isolation $P^{*}$ has increased for the Pakistani and Bangladeshi groups and decreased slightly for the White group. On average, White people live in areas with fewer White people than they did in 1991, while Pakistani and Bangladeshi people live in areas with more of their own group. This is consistent with the growth of the Pakistani and Bangladeshi populations during the decade (Figure 1). The high value of $P^{*}$ for White people - who are by far the most isolated group - shows again how the Index of Isolation is strongly related to overall population composition. None of the ethnic minority groups' index of isolation reaches $20 \%$, meaning that each lives in areas where on average more than $80 \%$ of the population are from other groups.

The number of 'polarised enclaves' remained at eight between 1991 and 2001. These are localities where White residents are less than $30 \%$ of the total, and one group accounts for at least two thirds of the non-White residents. There is not an increasing tendency toward 'ghettos', measured purely in terms of areas with a single dominant group. If mainly White areas are considered as ghettos, then their preponderance is 
reducing. The eight polarised enclaves are not the same at each census. Six were of Indian population in 1991 and four were of Pakistani population in 2001.

If the minority populations are increasing in size (some with slightly higher indices of isolation) and their evenness is increasing (slightly lower indices of dissimilarity) then one might expect that there has been migration away from the existing clusters. The Indices of Migration in Table 2 confirms this. Both White and non-White residents moved from the non-White areas (the fifth quintile for electoral wards in Table 1), in similar proportion to their population in those area (2.0\% and $1.4 \%$ respectively). And both White and non-White residents moved to the mainly White areas, proportionately increasing the non-White population more than the White population (1.1\% compared to $0.1 \%)$. This is strong evidence against 'retreat' into own areas, certainly for the non-White population. One could talk of White movement towards White areas, but the similarity of the movement for each group also suggests nonracial explanations such as limited housing in inner cities and movement toward better housing by those who can afford it.

Finally, the proportion of areas which are mixed, with $10 \%$ of both White and other populations, grew from 9\% to 12\% of all electoral wards between 1991 and 2001. The standardised Reciprocal Diversity Index likewise grew slightly. Greater diversity can be seen as a result both of population growth of the minority populations and of their movement away from original settlement areas. In the GLA report already mentioned, only ten of London's 630 wards were found to have decreased in diversity during the decade. In each case this was because of an increase in the White populations of those wards, not in the Black and Asian populations.

Table 3 shows the change in Indices of Dissimilarity and Polarisation between 1991 and 2001, both for England but also summarised for local authority Districts. Only those Districts whose boundaries have not changed between 1991 and 2001 have been included $^{2}$.

[Table 3 about here]

The median reduction in Index of Dissimilarity across Districts is considerably greater than for England and Wales as a whole, and is particularly marked for the Bangladeshi and Pakistani populations. This difference between the measured segregation across all wards of England and Wales, and the average of its values when measured across wards separately in each District, is an example of the impact of changes in the regional boundary, which will be discussed further in the next section. The interquartile range does suggest however, that the reduction in Index of Dissimilarity is persistent across most local districts. The populations of Pakistani and Bangladeshi origin (the main Muslim groups in Britain) have in particular become more evenly spread between localities. However, not too much should be made of the changes over time illustrated in Table 3, because they are also affected by ward boundary reviews, also discussed in the next section.

\section{Indices' behaviour in response to geographical boundaries}

Stan Openshaw (1984) showed that social indicators can take on apparently very different geographical patterns and relationships dependent on the boundaries of the localities compared. Three aspects of this Modifiable Area Unit Problem are now evaluated with respect to indices of residential segregation and diversity. 


\subsection{Impact of geographical scale}

Table 4 shows the same indices as already considered in Table 2, again for England and Wales, for the year 2001. The column for electoral wards repeats the column in Table 2 for ease of comparison, while the other columns present the indices' values when considering areas smaller than wards (Output Areas) and larger than wards (Districts).

[Table 4 about here]

In general, the same patterns are reproduced at each scale, but the clustering of groups is made clearer at smaller geographical scales. The Index of Dissimilarity shows greater unevenness between smaller areas than between larger areas, and the Index of Polarisation shows that each group lives in greater average proportion in its immediate vicinity than in its wider locality. The average proportion remains below $30 \%$ for each non-White group.

The average populations of the different sized areas decrease by a factor of approximately twenty from Districts $(138,409)$ to Wards $(5,880)$, and by a similar factor from Wards to Output Areas (297). The increase in both indices is similar when moving between the scales, for each group, suggesting a smooth impact of scale for each index. The exception is Bangladeshis for whom both indices increase noticeably faster when moving to the smallest scale. Thus is consistent with relatively small localised clusters.

Two results regarding scale are of importance when interpreting the changes over time presented in Table 2. First, the impact of scale is greater than the impact of changes over time. For example, the Index of Dissimilarity changes by between three and sixteen percentage points when moving from one scale to the next, compared to the decade changes of two to three percentage points. Unless the size of locality population is approximately maintained, one cannot fairly compare across cities of different countries or across time. For example, the size of the smallest census area in the UK census reduced by one third between 1991 and 2001: comparisons over time at that geographical scale may be misleading. Second, the number of wards did reduce between 1991 and 2001, such that their average population increased from 5,247 to 5,880 . This change by a factor of 1.1 is likely to have contributed to the reduction in unevenness during the decade observed in Table 2, but only marginally and certainly not to account for it all. Since a factor of 20 produced changes of a maximum sixteen percentage points, a factor of 1.1 is likely to have produced changes below 0.1 percentage points.

As one would expect the number of polarised enclaves (dominated by one non-White group) rises rapidly for smaller geographical units because the groups are relatively small in the total population and are more likely to be the majority in a small residential area. For the same reason, the percentage of areas which are Mixed is greater when measured for the smallest areas. However, the percentage of areas which are Mixed is lower for Wards than for Districts, a pattern repeated for the standardised Reciprocal Diversity Index. This is almost certainly a result of the concentration of small-population wards in unmixed White rural areas. This depresses the scores of average diversity used here, which do not take account of the relative sizes of each locality population.

The pattern of migration away from areas of existing non-White population and towards mainly White areas is reproduced at each geographical scale. The net 
movement away from existing areas of non-White population is rather less when measured for Districts, suggesting that much of the movement is to other areas within the same Districts. The similarity of migration patterns of White and other residents within the UK noticed above for wards is even more evident when measured for either Output Areas or Local Authority Districts.

\subsection{Impact of regional boundary}

In Tables 2 and 4, the regional boundary within which localities are compared was the whole of England and Wales. In many research studies the regional boundary is a local city area, and the segregation of different regions is compared. A priori one might expect some impact of where the regional boundary is drawn. Manchester local authority for example is bounded tightly around an urban area, whereas Bradford local authority includes a large population in rural areas which are predominantly White. The inclusion of those rural areas is likely to increase the indices of segregation and reduce the measures of diversity.

Table 5 demonstrates this effect by categorising the 2001 Census Output Areas as below or above the median population density. The dense half of Output Areas are the most urban, and can be thought of as a tightly bounded urban version of England and Wales. Considering only those areas, the indices do suggest less unevenness (Index of Dissimilarity), greater average proportions (Index of Isolation) and greater diversity within the dense areas. The difference is of the same order as the changes in index values between 1991 and 2001, and affects all indices.

[Table 5 about here]

\subsection{Impact of locality boundaries}

In the UK and to a differing degree in other countries, the boundaries of localities used for population statistics are reviewed and change regularly. In this section the impact of such boundary changes is discussed with reference to the two Urban Areas identified by the State of English Cities report as moving against the trend of decreasing segregation between White and other residents. "There are only eight cities ... where segregation has increased over the past decade. In only two cases was it by a significant amount, Blackburn +0.08 and Norwich +0.06 ” (Parkinson et al., Vol 1, 153). The report measured the Index of Dissimilarity using the same census data for electoral wards in 1991 and 2001 that has been used in this paper for Table 2.

Table 6 shows the Indices of Dissimilarity and Isolation for four regions including the Blackburn and Norwich Urban Areas as defined in State of the Cities report. The first two lines for each region show the measurement direct from the two censuses. The 2001 Census output for wards uses the boundaries available at the time of output, at the end of 2003. These first lines show the increase in the Index of Dissimilarity noted by the State of the Cities Report for both Urban Areas. A decrease is recorded for the other two areas shown, Bradford and Calderdale as is more general in Britain. Table 6 also illustrates some of the earlier results from this paper. The Index of Isolation tends to be lower where the proportion of population in groups other than White is low (Norwich). The Index of Dissimilarity tends be lower where the average ward size is relatively large (Bradford compared to Blackburn), but it is also lower when the nonWhite population is small (Norwich).

[Table 6 about here] 
Electoral boundaries have changed since 1991 in all four regions. In Blackburn and in Norwich the changes were between census output dates. The third line recalculates one of the year's indices using census data which has been reprocessed to allow comparison over time. In Blackburn this is achieved by converting 1991 data to 2003 ward boundaries.

In Blackburn, the increase in Index of Dissimilarity from 0.58 to 0.66 is seen to be purely a result of boundary changes: there is no change at all when using consistent boundaries. The use of consistent boundaries has reduced the disparity between Blackburn and national change in Index of Dissimilarity (-0.03, from Table 3) from 11 percentage points to 3 percentage points. On the other hand, an increase in the Index of Isolation is still apparent when measured with consistent boundaries, as expected from a growing Asian population.

In Bradford and Calderdale, ward boundaries did not change between censuses. Boundary reviews after the Census, in 2004, resulted in higher measured segregation for 2001 when measured for the new localities. There may a tendency in areas of diverse population, to redraw electoral boundaries that respect to some extent the visible demarcations of ethnic group.

Norwich presents a different story that further suggests the need for a times series with consistent definition of population categories. Although the number of wards reduced in Norwich Urban Area, the Index of Dissimilarity increased between the two censuses. This is contrary to the general expectation of lower dissimilarity with higher ward populations. When 2001 data is recast onto 1991 boundaries for comparison, the increase in unevenness persists. In this case the comparison suffers from a change in population definition between the two censuses; the 1991 Census counts students at their vacation address and the 2001 Census at their term-time address. Norwich has a major University so that in 2001, the population of that the eponymously named University ward had nearly doubled between 1991 and 2001 and the number of nonWhite residents in had trebled. The increase will be partly due to the change in counting method and partly due to a real increase in student numbers during that period. These were not the changes that the State of the Cities report's use of a segregation index was intended to monitor.

\section{Interpretation and conclusions}

When immigration leads to established residence of significant new populations with common overseas origin, the composition of local areas changes over a period of several decades. This section reviews the changes highlighted by indices of segregation and diversity, discusses the appropriate use of these indices and the consequences of their misuse, and suggests alternative approaches to measuring local population change.

\subsection{Population change after immigration}

Implementation of indices of segregation and diversity has provided a clear indication of strong trends. The Index of Dissimilarity has shown a decrease in the unevenness of residence between each ethnic group and the rest of the population. This decrease in unevenness has occurred for all groups, but is greatest for the mainly Muslim Pakistani and Bangladeshi groups for whom concern about segregation has been voiced most loudly. This paradox is somewhat explained by the simultaneous growth of visible Black and Asian populations throughout England and Wales. As a 
consequence the Index of Isolation has increased for the fastest growing groups, the same Pakistani and Bangladeshi populations. The ‘isolation' referred to is the average proportion of one's own group across all the areas where the group lives. It does not reach $30 \%$ for any non-White ethnic group even when measured for the smallest census areas of $200-400$ households. $100 \%$ would represent complete isolation from other groups.

The increased ethnic minority population has not resulted in an increase in the number of localities dominated by one ethnic group. Instead there are more mixed areas and more diversity. The combination of increased population and increased evenness of population geography is confirmed by migration away from the areas of least White population, towards predominantly White areas. This migration is of the same order for both White and non-White residents.

Putting these results against the claims that motivate much of the anxieties about the 'colour' of localities, there has not been increased segregation in the sense of more uneven distribution of ethnic groups across localities. Neither is there self-segregation in the sense of minority groups moving towards their existing areas of highest concentration. White flight also appears to be a misnomer; the average movement away from the most non-White areas is not greater for White people than for others.

Historical studies of Huguenot, Jewish and Irish immigration show many parallels with more recent immigration based in labour shortages answered from other British colonies in the past half-century. In those historical studies, early clustering has been seen as social solidarity in a strange and largely unwelcoming land, enabling integration and later dispersal as experience increases in the labour and housing markets (for example Gwynn 2002; Busteed 2000; Waterman and Kosmin 1987).

Whether historically or recently, natural population increase and further chain immigration tend to fill up the original settlement areas, creating housing pressure for all local residents. Dispersal from these areas is then inevitable, either to neighbouring areas (which has the effect of enlarging the visible cluster) or to areas further away where family resources allow it. Both the population growth and the dispersal should be expected. It has stabilised for the Caribbean population, is in full swing for the Indian group, and will continue for some decades for the Pakistani and Bangladeshi groups. In the long run one should not expect a residential melting pot but more a mosaic (Peach, 1996). Clusters will remain as with the Jewish population whose main migration to Britain was a century ago. The Jewish population nonetheless has the highest Index of Dissimilarity in England and Wales among groups defined by religious affiliation recorded in the 2001 Census (Dorling and Thomas, 2004).

Other research results support this twin notion of population growth and dispersal, and reject the notion of increasing segregation. This supporting research includes subnational demographic analysis making full use of census data (Rees 2005; Simpson 2005; Simpson et al., 2006), and qualitative work with Asian households (Phillips, 2006; Harrison et al., 2005). The increasing social spatial segregation found over three decades by Dorling and Rees (2003) may ironically be a root of decreasing racial spatial segregation: new communities from immigration not only come of age demographically but divide along English class lines and migrate accordingly.

In short, the rich data of the population census does not support the much-publicised claims of increasing segregation and the creation of ghettos. Instead, the behaviour of the indices of segregation and diversity reflect the demographic consequences of 
relatively recent immigration streams. The young age composition of immigrants creates an engine for population growth for several decades before the original immigrants become elderly. Greater diversity, and more Mixed areas are to be expected, as are many smaller clusters in less urban areas as dispersal becomes more noticeable than population growth. European experience of changing ethnic composition will continue to be multi-dimensional in the way illustrated here for England and Wales because it is also based on recent immigration, in contrast to the residential patterns of the established Black and White populations in the USA where segregation indices were developed.

\subsection{Appropriate and inappropriate use of indices of segregation and diversity}

The pressure for a single index to answer politicians' anxieties about segregation is strong. Even Massey and Denton who so forcefully argued for the multi-dimensional picture of residential patterns (1988) which this paper supports, later used a scale of 'hypersegregation' to identify cities that were segregated on all their five dimensions (1989). That approach is not appropriate when it is clear that the indices are changing in opposite directions for some groups.

Both the common indices of segregation have straightforward interpretations. The proportion of a group that would have to move to be distributed through localities like the rest of the population (the Index of Dissimilarity) and the average proportion of a group across all localities, (the Index of Isolation) can be usefully employed to respectively describe the evenness and the exposure of each ethnic group. However, both are crude summary measures of residential patterns and are not amenable to change through policy. They do not describe any of the multiple factors that cause local population change and therefore cannot isolate the particular factors that social policy may be able to influence. In particular, the natural population growth of the non-White populations will continue to keep both indices high, and to push up the exposure indices that reflect population composition. Since policy does not generally ask people to have fewer children or to die younger, this growth is not properly a policy concern. The number of localities with more than any stated proportion of nonWhite residents is likely to increase for some time (though there are currently no Wards with less than 10\% White), and certainly as long as population growth exceeds the dispersal from existing areas of greatest immigrant settlement. Is there reason to view these areas as segregated any more than one would areas which are more than a stated proportion White (7,771 of the 8,850 Wards of England and Wales in 2001 were more than $90 \%$ White)? To use indices of exposure based on the proportion of non-White groups in an area, in a normative or evaluative manner seems to be prejudicial to areas on the basis of their colour.

Among the measures considered here, the direction of migration and the trend in evenness ought to be preferred as measures of change in residential patterns which do reflect more closely the housing market which policies can aim to influence.

The analyses have shown that the indices are sensitive to regional boundaries, to small area boundaries within the region of study and to the scale or mean population size of the small areas. The impact of each of these modifiable aspects of areal units has been shown in practice to be at least as great as the observed change in the index values over a decade. There are three important consequences. First, there can be no norm for 'high' segregation. Second, comparisons between countries or cities' segregation is misleading if used as an evaluation of performance. Third, comparison over time is misleading unless referring to consistent boundaries and population definitions. The 
lack of such consideration allows extreme changes in the indices to be interpreted erroneously as has happened recently in government assessment of social cohesion in English cities.

Attempts to compare school segregation with neighbourhood segregation are similarly misleading unless they construct and compare equivalent catchment areas. When this is not done, small differences in indices of segregation are woefully inadequate as measures of the impact of parental choice, as used for example by Burgess et al (2005).

\subsection{Alternative approaches to measuring local population change and concern with ghettos}

There are many factors which make up the changing geographical pattern of social groups, which can be better measured than by the indices discussed in this paper. With the exception of the Index of Migration they measure only the pattern of residence rather than the processes that produce that pattern. Demographic methods can model and predict local change expected in populations of young adults associated with immigration. An understanding of this purely demographic pressure on housing is a priority.

Demographic pressure is only one factor in dispersal from poor inner city housing where economic immigrants are often placed after arrival. Social policy should also aim to understand the importance of family and cultural ties, including the role of shops, services and religious facilities, and the perceptions of safety and suitability (the environment and type of housing) of potential destination areas. These are things which government regional and local policy can affect.

Equality, interaction and participation are three aspects of integration which are highlighted by the Commission for Racial Equality in Britain. Inequality between ethnic groups in the labour market is as great in predominantly White areas in Britain as in diverse inner city areas (Simpson et al, 2006). Census data allow measurement of concentrated poor local social, housing and employment conditions which are an integral part of the notion of a ghetto for they identify the economic incapacity of residents to escape. Interaction and participation are perhaps more suited to qualitative studies than to population estimation. Just as a residential 'mosaic' may be expected, there need be no assumptions that interaction and participation will be of the same nature for every person. Sufficient interaction for comfortable, trusted, safe cities is compatible with preferences that maintain social and family networks.

The response of indigenous residents to the changing diversity of their neighbourhood is a further area of political concern which is not well served by any of the indices of segregation and diversity examined here. While this paper has shown there is no net White flight from highly non-White areas, such analysis could and should go much further. What is the pattern of migration for each group from areas of other concentrations and how can it be explained in terms of economic and social changes and aspirations? Is the net out-migration of White residents more or less than other areas of different ethnic make up? To what extent is there avoidance of some areas: less in-migration, rather than more out-migration, as suggested by Brama (2006) for Sweden? Many inner city areas are areas of great 'churn' of temporary residents. It may be that large immigrant populations are the most stable part of those areas.

These various paths open for productive research on the changing diversity of urban and not-so-urban localities may take understanding and social policy further than 
continued focus on segregation indices. In Britain a consistent time series of population estimates would help this research, extending to smaller areas the current experimental tabulations of ethnic group by age and sex for local authority Districts published by the Office for National Statistics (ONS, 2006). Current work at the University of Manchester aims to create a consistent time series backwards to link the 1991 and 2001 censuses for ethnic group, age, sex and small localities.

\subsection{Conclusions}

This paper brings good news from census analysis to suggest that a doom-laden view of increasing segregation and the threat of ghettos is not supported by the evidence. Perhaps one can expect pessimistic insistence on the ethnic dimension of geography to continue. Anxiety about other people's colour and origins has long affected demographic and statistical study and it may be premature to hope for a reduction in the use of crude indices of segregation and the assumption that high values have negative connotations. The statistics in this paper suggest that the anxieties are better seen as ghettos of the mind rather than ghettos of reality.

Analysis of indices of segregation and diversity show more mixing through a natural process of growth of immigrant-origin populations and a greater evenness of population distribution. But these indices do not include the poor educational, housing and employment conditions which do deserve concerted attention and which are also shown by the census to be focused on some social groups, disproportionately associated with ethnic minority populations. Nor do the indices help to mobilise the positive aspects of social networks within residential clusters which support integration in the longer term.

\section{Notes}

${ }^{1}$ The comparable groups are derived from work on stability of ethnic group for individuals measured across censuses in the Longitudinal Study (Simpson and Akinwale, 2007). Figure 1 also takes into account census non-response estimated for both censuses.

${ }^{2}$ Minor boundary changes are made by the Boundary Commissions during a decade. During the 1990s, a major reorganisation of local authorities affected the whole of Great Britain. For this analysis, the 281 unchanged local authorities in England and Wales have been used, according to two criteria: 99\% of addresses in the 1991 boundary were retained in the 2001 boundary, and 99\% of addresses in the 2001 boundary were also in the 1991 boundary, using the geographical conversion tables documented in Simpson and Yu (2003). 


\section{Acknowledgements}

Census data are Crown Copyright. Daniel Neff and Nissa Finney helped with data preparation for mixed areas and migration respectively. Elise Carroll, Roger Denton, Wendy Pontin, Bradford Community Statistics Project and David Cant supplied census data for Blackburn with Darwen, Norwich and Broadland, Bradford and Calderdale Council areas used in Table 6.

\section{References}

Brama, A. (2006) "White flight"? The production and reproduction of immigrant concentration areas in Swedish cities, 1990 - 2000, Urban Studies, 43(7).

Burgess, S., Wilson, D. and Lupton, R. (2005) Parallel lives? Ethnic segregation in schools and neighbourhoods, Urban Studies, 42(7): 1027-1056.

Busteed M A (2000) Little Islands of Erin: Irish Settlement and identity in MidNineteenth-Century Manchester in MacRaild D $\mathrm{M}$ ed The Great Famine and Beyond. Irish Migrants in Britain in the Nineteenth and Twentieth Centuries Irish Academic Press, Dublin 94-127.

Cantle, Ted (2001) Community Cohesion: a report of the Independent review Team. London: Home Office.

Coleman D and J Salt (1996) Ethnic group measurement in Europe. In Coleman and Salt (eds) Ethnicity in the 1991 census: volume 1. HMSO, London. (to complete)

CRE (2005) Social relations of Asian young adults and parents. http://cre.gov.uk

Dorling, D. and Rees, P. (2003) A nation still dividing: the British census and social polarisation 1971 - 2001, Environment and Planning A, 35(7): 1287 - 1313.

Dorling D and Thomas B (2004) People and Places: a 2001 Census atlas of the UK, Bristol: Policy Press.

Duncan OD and B Duncan (1955) A methodological analysis of segregation measures. American Sociological Review 20: 210-217.

Fortuijn, J. D., Musterd, S. and Ostendorf, W. (1998) International migration and ethnic segregation: impacts on urban areas, Urban Studies, 35(3): 367-370.

GLA (2005) London's changing population, diversity of a world city in the 21st century. London: Greater London Authority Data Management and Analysis Group Briefing 2005/39.

Gorard, S. and Taylor, C. (2002) What is segregation, a comparison of measures in terms of 'strong' and 'weak' compositional invariance, Sociology, 36(4): 875-895.

Gwynn R (2002) Huguenot Heritage: The History and Contribution of the Huguenots in Britain $3^{\text {rd }}$ Ed. Routledge/Kegan Paul, London

Harrison, M., Phillips, D., Chahal, K., Hunt, L. and Perry, J. (Eds.) (2005) Housing, 'race' and community cohesion, Chartered Institute of Housing, Coventry.

Johnson, N. (2006) Race is too often sidelined from major policy developments, The Guardian 1st March

Johnston, R., Forrest, J. and Poulsen, M. (2002) Are there ethnic enclaves/ghettos in English cities?, Urban Studies, 39(4): 591-698.. 
Johnston, R., Wilson, D. and Burgess, S. (2004) School segregation in multi-ethnic England, Ethnicities, 4(2): 237-265.

Lieberson S (1963) Ethnic Patterns in American Cities The Free Press of Glencoe, New York

Massey, D. and Denton, N. (1988) The dimensions of residential segregation, Social Forces, 67: 281-315.

Massey, D. and Denton, N. (1989) Hypersegregation in US metropolitan areas: Black and Hispanic segregation along five dimensions, Demography, 26: 373-393.

ONS (2006) Population estimates by ethnic group (experimental) http://www.statistics.gov.uk/StatBase/Product.asp?vlnk=14238, Office for National Statistics, Titchfield.

Openshaw, S. (1984) The modifiable areal unit problem. CATMOG38, Geo Books, Norwich.

Ouseley, Herman (2001) Community pride not prejudice, making diversity work in Bradford. Bradford: Bradford Vision.

Parkinson, M., Champion, T., Evans, R., Simmie, J., Turok, I., Crookston, M., Katz, B., Park, A., Berube, A., Coombes, M., Dorling, D., Glass, N., Hutchins, M., Kearns, A., Martin, R. and Wood, P. (2006) State of the English Cities (2 vols), Office of the Deputy Prime Minister, London.

Peach, C. (1996) Does Britain have ghettoes?, Transactions, Institute of British Geographers, 21(1): 216-235.

Peleman, K (2002) The impact of residential segregation on participation in associations: the case of Moroccan women in Belgium. Urban Studies 39(4): 727747.

Phillips T (2005) After 7/7: Sleepwalking to segregation, speech to the Manchester Council for Community Relations, $22^{\text {nd }}$ September. http://www.cre.gov.uk

Phillips, D. (2006) Parallel lives? Challenging discourses of British Muslim selfsegregation, Environment and Planning D: Society and Space, 24(1): 25-40.

Poulsen, M., Johnston, R. and Forrest, J. (2004) Is Sydney a divided city ethnically? Australian Geographical Studies, 42(3): 356-377.

Rees, P. (2005) Estimating international migration at the regional scale for ethnic groups in the UK, In Workshop on International Migration, Social Science Research Institute, University of Southampton and the Netherlands Interdisciplinary Demographic Institute, University of Southampton.

Rex, J (1981) Urban segregation and inner city policy in Great Britain. Pages 25-42 in C Peach, C Robinson and S Smith (eds), 1981, Ethnic segregation in cities. London: Croom Helm.

SEU (2000) National strategy for neighbourhood renewal: Report of Policy Action Team 18 - Better Information, Cabinet Office, Social Exclusion Unit, The Stationery Office, London.

Simpson L (2004) Statistics of racial segregation: measures, evidence and policy Urban Studies 41(3): 661-681 
Simpson, L. (2005) Measuring residential segregation, Conference presentation with data files Census: present and future, Leicester, available from http://www.ccsr.ac.uk/research/migseg.htm

Simpson, L. and Akinwale, B. (2007) Quantifying stability and change in ethnic group, Journal of Official Statistics. Accepted subject to revision

Simpson, L. and Gavalas, V. (2005) Population forecasts for Stoke-on-Trent

UA, with an ethnic group dimension, CCSR Working Paper 2005-01, University of Manchester, Manchester.

Simpson, L, V Gavalas and N Finney (2006, under review) Population dynamics in ethnically diverse towns: the long-term implications of immigration. Transactions of the Institute of British Geographers.

Simpson, L. and Yu., A. (2003) Public access to conversion of data between geographies, with multiple look up tables derived from a postal directory, Computers, Environment and Urban Systems, 27: 283-307.

Voas, D. and Williamson, P. (2000) The scale of dissimilarity: concepts, measurement and an application to socio-economic variation across England and Wales, Transactions, Institute of British Geographers, 25: 465-481.

Waterman S and Kosmin B A (1987) Residential patterns and processes: a study of Jews in three London boroughs Transactions of the Institute of British Geographers 13: $79-95$

White, MJ (1986) Segregation and diversity: measures in population distribution Population Index 52: 198-221.

Williamson, L. (2003) Population projections of minority ethnic groups in England: what can we conclude from the differences with the 2001 census?, In British Society for Population Studies Annual Conference, Bristol.

Wirth, L. (1928) The Ghetto. University of Chicago Press, Chicago.

Zuberi, T. (2001) Thicker than blood: how racial statistics lie, University of Minnesota Press, Minneapolis. 
Table 1. Distribution of population, quintiles of ethnic groups other than White

\begin{tabular}{|c|c|c|c|c|c|}
\hline & \multirow[b]{2}{*}{$\begin{array}{c}\text { Number } \\
\text { of areas }\end{array}$} & \multicolumn{2}{|c|}{$\begin{array}{c}\text { Population Not } \\
\text { White }\end{array}$} & \multicolumn{2}{|c|}{ White Population } \\
\hline & & Number & $\begin{array}{l}\text { Per } \\
\text { cent }\end{array}$ & Number & $\begin{array}{r}\text { Per } \\
\text { cent }\end{array}$ \\
\hline \multicolumn{6}{|l|}{ (a) Local Authority } \\
\hline All Districts & 376 & $4,521,050$ & $9 \%$ & $47,520,866$ & $91 \%$ \\
\hline 1 Fewest Not White pop & 306 & 903,385 & $3 \%$ & $33,451,363$ & $97 \%$ \\
\hline 2 Low Not White pop & 37 & 863,958 & $11 \%$ & $6,820,269$ & $89 \%$ \\
\hline 3 Medium Not White pop & 16 & 886,917 & $19 \%$ & $3,722,401$ & $81 \%$ \\
\hline 4 High Not White pop & 11 & 958,149 & $33 \%$ & $1,902,498$ & $67 \%$ \\
\hline 5 Highest Not White pop & 6 & 908,641 & $36 \%$ & $1,624,335$ & $64 \%$ \\
\hline \multicolumn{6}{|l|}{ (b) Electoral wards } \\
\hline All Wards & 8,850 & $4,521,048$ & $9 \%$ & $47,520,868$ & $91 \%$ \\
\hline 1 Fewest Not White pop & 7,554 & 904,007 & $2 \%$ & $37,376,562$ & $98 \%$ \\
\hline 2 Low Not White pop & 726 & 903,762 & $13 \%$ & $6,077,788$ & $87 \%$ \\
\hline 3 Medium Not White pop & 288 & 903,894 & $27 \%$ & $2,411,771$ & $73 \%$ \\
\hline 4 High Not White pop & 180 & 900,383 & $43 \%$ & $1,180,437$ & $57 \%$ \\
\hline 5 Highest Not White pop & 102 & 909,002 & $66 \%$ & 474,310 & $34 \%$ \\
\hline \multicolumn{6}{|l|}{ (c) Output Areas } \\
\hline All Output Areas & 175,434 & $4,521,162$ & $9 \%$ & $47,520,754$ & $91 \%$ \\
\hline 1 Fewest Not White pop & 136,341 & 904,228 & $2 \%$ & $39,052,134$ & $98 \%$ \\
\hline 2 Low Not White pop & 20,892 & 904,189 & $14 \%$ & $5,338,139$ & $86 \%$ \\
\hline 3 Medium Not White pop & 9,511 & 904,272 & $32 \%$ & $1,959,102$ & $68 \%$ \\
\hline 4 High Not White pop & 5,583 & 904,181 & $51 \%$ & 880,345 & $49 \%$ \\
\hline 5 Highest Not White pop & 3,107 & 904,292 & $76 \%$ & 291,034 & $24 \%$ \\
\hline
\end{tabular}


Table 2. Indices of segregation and diversity, for wards of England and Wales

\begin{tabular}{llrr}
\hline & & $\mathbf{1 9 9 1}$ & $\mathbf{2 0 0 1}$ \\
\hline 1. Evenness & & & \\
\hline Index of Dissimilarity & White & 61 & 59 \\
& Caribbean & 69 & 67 \\
& Indian & 65 & 62 \\
& Pakistani & 75 & 72 \\
& Bangladeshi & 74 & 72 \\
& & & \\
\hline 2. Exposure & & & \\
\hline Index of Isolation & White & 95 & 93 \\
& Caribbean & 8 & 7 \\
& Indian & 16 & 15 \\
& Pakistani & 14 & 17 \\
& Bangladeshi & 11 & 14
\end{tabular}

\begin{tabular}{|c|c|c|c|}
\hline $\mathbf{N}$ of polarised enclaves & & 8 & 8 \\
\hline \multicolumn{4}{|l|}{ 3. Movement } \\
\hline \multicolumn{4}{|l|}{$\begin{array}{l}\text { Migration index (net } \\
\% \text { moving into Non- }\end{array}$} \\
\hline \multirow[t]{2}{*}{ White areas) } & White & & -2.0 \\
\hline & All others & & -1.4 \\
\hline \multirow{3}{*}{$\begin{array}{l}\text { Migration index (net } \\
\% \text { moving into White } \\
\text { areas) }\end{array}$} & & & \\
\hline & White & & 0.1 \\
\hline & All others & & 1.1 \\
\hline \multicolumn{4}{|l|}{ 4. Diversity } \\
\hline \multicolumn{4}{|l|}{ \% Mixed areas (with } \\
\hline \multicolumn{4}{|l|}{$10 \%$ each of White } \\
\hline \multicolumn{4}{|l|}{ Reciprocal Diversity } \\
\hline Index & & 1.07 & 1.78 \\
\hline
\end{tabular}

Indices as defined in text, multiplied by 100. 
Table 3. Indices of segregation and diversity, for wards

Change over time for England and Wales, and for local authority Districts

\begin{tabular}{|c|c|c|c|c|c|}
\hline & & \multirow{2}{*}{$\begin{array}{r}\text { Wards in } \\
\text { England } \\
\text { and Wales, } \\
\text { change } 1991 \\
\text { to } 2001\end{array}$} & \multicolumn{3}{|c|}{$\begin{array}{c}\text { Wards in local authority Districts, } \\
\text { change } 1991 \text { to } 2001 *\end{array}$} \\
\hline & & & Median & $\begin{array}{l}\text { Lower } \\
\text { quartile }\end{array}$ & $\begin{array}{r}\text { Upper } \\
\text { quartile }\end{array}$ \\
\hline \multicolumn{6}{|l|}{ 1. Evenness } \\
\hline \multirow[t]{5}{*}{ Index of Dissimilarity } & White & -2.6 & -3.4 & -6.7 & -0.8 \\
\hline & Caribbean & -1.8 & -2.8 & -7.8 & 5.1 \\
\hline & Indian & -3.1 & -4.2 & -8.3 & -0.3 \\
\hline & Pakistani & -3.4 & -7.7 & -14.9 & -3.3 \\
\hline & Bangladeshi & -2.6 & -7.5 & -14.3 & -2.0 \\
\hline \multicolumn{6}{|l|}{ 2. Exposure } \\
\hline \multirow[t]{5}{*}{ Index of Isolation } & White & -1.9 & -0.9 & -1.9 & -0.5 \\
\hline & Caribbean & -0.3 & 0.0 & -0.1 & 0.0 \\
\hline & Indian & -0.1 & 0.1 & 0.0 & 0.2 \\
\hline & Pakistani & 3.5 & 0.1 & 0.0 & 0.3 \\
\hline & Bangladeshi & 2.9 & 0.0 & 0.0 & 0.2 \\
\hline
\end{tabular}

Indices as defined in text, multiplied by 100

* 281 local authority Districts with unchanged boundaries have been included. 
Table 4. Indices of segregation and diversity in 2001, for different units of analysis

England and Wales, 2001

\begin{tabular}{|c|c|c|c|c|}
\hline & Mean population & $\begin{array}{r}\text { Output } \\
\text { Area } \\
297 \\
\end{array}$ & $\begin{array}{r}\text { Ward } \\
5,880 \\
\end{array}$ & $\begin{array}{r}\text { Local } \\
\text { Authority } \\
\text { District } \\
138,409 \\
\end{array}$ \\
\hline \multicolumn{5}{|l|}{ 1. Evenness } \\
\hline \multirow{5}{*}{ Index of Dissimilarity } & White & 62 & 59 & 52 \\
\hline & Caribbean & 72 & 67 & 63 \\
\hline & Indian & 69 & 62 & 56 \\
\hline & Pakistani & 79 & 72 & 62 \\
\hline & Bangladeshi & 88 & 72 & 61 \\
\hline \multicolumn{5}{|l|}{ 2. Exposure } \\
\hline \multirow[t]{5}{*}{ Index of Isolation } & White & 94 & 93 & 93 \\
\hline & Caribbean & 9 & 7 & 5 \\
\hline & Indian & 20 & 15 & 9 \\
\hline & Pakistani & 26 & 17 & 6 \\
\hline & Bangladeshi & 21 & 14 & 10 \\
\hline $\mathrm{N}$ of polarised enclaves & & 839 & 8 & 0 \\
\hline \multicolumn{5}{|l|}{ 3. Movement } \\
\hline \multirow[t]{2}{*}{$\begin{array}{l}\text { Migration index (net \% } \\
\text { moving into Non-White } \\
\text { areas) }\end{array}$} & White & -2.3 & -2.0 & -0.8 \\
\hline & All others & -2.0 & -1.4 & -0.6 \\
\hline \multirow[t]{2}{*}{$\begin{array}{l}\text { Migration index (net \% } \\
\text { moving into White areas) }\end{array}$} & White & 0.1 & 0.1 & 0.2 \\
\hline & All others & 0.4 & 1.1 & 0.7 \\
\hline \multicolumn{5}{|l|}{ 4. Diversity } \\
\hline $\begin{array}{l}\text { \% Mixed areas (with } 10 \% \\
\text { each of White and other) }\end{array}$ & & 20 & 12 & 15 \\
\hline Reciprocal Diversity Index & & 2.78 & 1.78 & 1.99 \\
\hline
\end{tabular}


Table 5. Indices of segregation and diversity in 2001 in densely populated areas England and Wales, 2001

\begin{tabular}{|c|c|c|c|}
\hline & & $\begin{array}{r}\text { All } \\
\text { Output } \\
\text { Areas } \\
\end{array}$ & $\begin{array}{r}\text { Densely } \\
\text { populated } \\
\text { half of } \\
\text { Output } \\
\text { Areas } \\
\end{array}$ \\
\hline \multicolumn{4}{|l|}{ 1. Evenness } \\
\hline \multirow[t]{5}{*}{ Index of Dissimilarity } & White & 62 & 61 \\
\hline & Caribbean & 72 & 66 \\
\hline & Indian & 69 & 66 \\
\hline & Pakistani & 79 & 76 \\
\hline & Bangladeshi & 88 & 82 \\
\hline \multicolumn{4}{|l|}{ 2. Exposure } \\
\hline \multirow[t]{5}{*}{ Index of Isolation } & White & 94 & 91 \\
\hline & Caribbean & 9 & 10 \\
\hline & Indian & 20 & 23 \\
\hline & Pakistani & 26 & 29 \\
\hline & Bangladeshi & 21 & 23 \\
\hline
\end{tabular}

\begin{tabular}{lrr}
\hline 4. Diversity & & \\
\hline $\begin{array}{l}\text { \% Mixed areas (with 10\% } \\
\text { each of White and other) }\end{array}$ & 20 & 31 \\
\hline Reciprocal Diversity Index & 2.78 & 4.26 \\
\hline
\end{tabular}

Indices as defined in text, multiplied by 100. Migration index not available for dense areas. 
Table 6: Index of Dissimilarity before and after ward boundary reviews

\begin{tabular}{lrrrr}
\hline $\begin{array}{l}\text { Regions } \\
\text { (Mean ward population, \% } \\
\text { non-White in 2001) }\end{array}$ & $\begin{array}{r}\text { Year } \\
\text { of data }\end{array}$ & $\begin{array}{r}\text { Year of ward } \\
\text { boundaries } \\
\text { (number of } \\
\text { wards) }\end{array}$ & $\begin{array}{r}\text { Index of } \\
\text { Dissimilarity }\end{array}$ & $\begin{array}{r}\text { Index of } \\
\text { Isolation }\end{array}$ \\
\hline Blackburn Urban Area & 1991 & $1991(21)$ & 58 & $P^{*}$ \\
(5.9k, 15.4\%) & 2001 & $2003(23)$ & 66 & 53 \\
& 1991 & $2003(23)$ & 66 & 44 \\
\hline Norwich Urban Area & 1991 & $1991(51)$ & 23 & 2 \\
(6.0k, 2.2\%) & 2001 & $2003(40)$ & 27 & 3 \\
\cline { 2 - 4 } & 2001 & $1991(51)$ & 27 & 4 \\
\hline Bradford & 1991 & $1991(30)$ & 57 & 40 \\
(15.6k, 21.7\%) & 2001 & $2001(30)$ & 56 & 47 \\
& 2001 & $2004(30)$ & 63 & 51 \\
\hline Calderdale & 1991 & $1991(18)$ & 58 & 17 \\
(10.7, 7.0\%) & 2001 & $2001(18)$ & 53 & 20 \\
& 2001 & $2004(17)$ & 57 & 35 \\
\hline
\end{tabular}

The mean ward population is of all groups from 2001 Census output, in thousands. Indices as defined in text, multiplied by 100. Each index is calculated from data for electoral wards within the indicated local authority, except Norwich Urban Area which also includes electoral wards in Broadland. The indices refer to 'non-White' groups taken as a whole. 
Figure 1: Population change 1991-2001

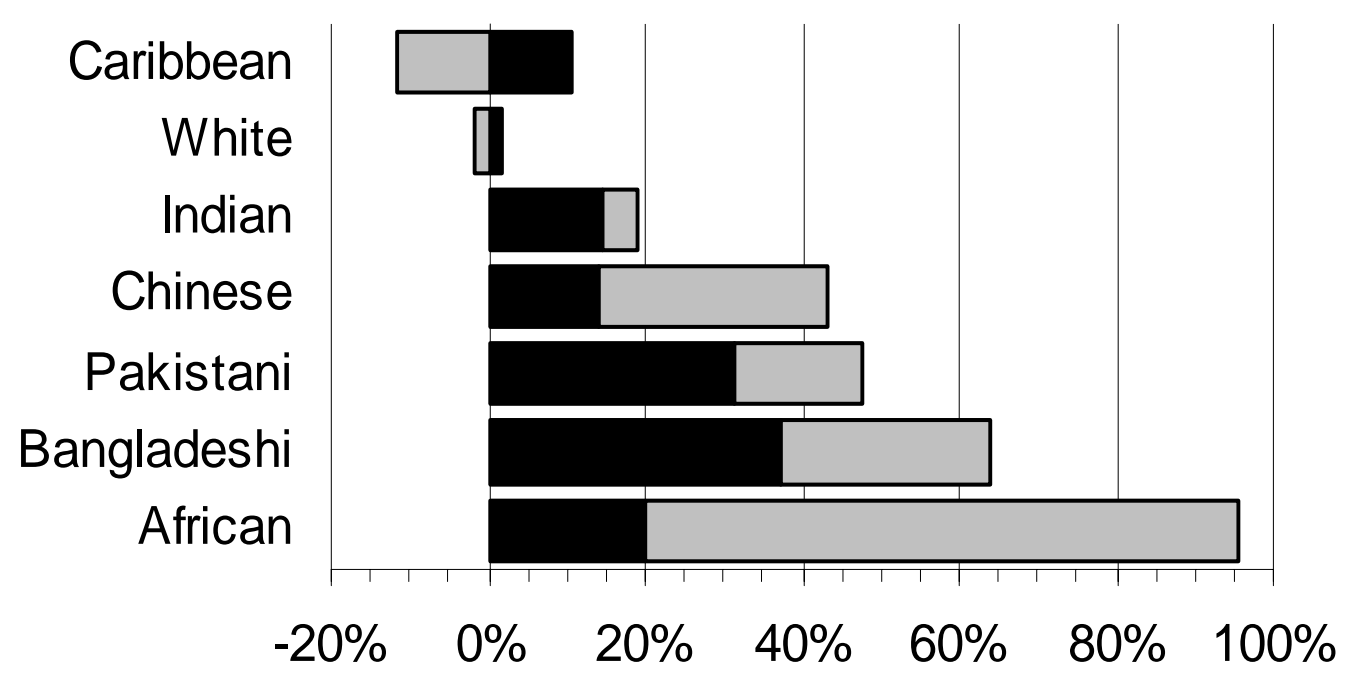

Black: natural change (excess of births over deaths). Grey: Net migration. Source: Williamson (2003) 